\title{
Exploration on Hunan Province's folk arts in package designing course of local university
}

\author{
Lu Ning \\ Hunan Arts and Crafts Vocational College \\ Yiyang , Hunan ,413000, China
}

\begin{abstract}
The folk arts of Hunan province is the name card of Huxiang culture, which can demonstrate the artistic glamour of Huxiang culture. Through thousands of years, the folk arts of Hunan Province is less and less applied with the development of the times, however, in the teaching of package designing course, it can not only promote the visual images of Hunan's local package designing and manifests the artistic charming of local folk arts but also can inherit and develop the local folk arts in contemporary society by guiding the students applying the elements of folk arts into the practice of package designing courses.
\end{abstract}

Keywords-) folk arts of Hunan Province; specialty; package designing; courses; teaching practices

\section{THE RELATIONSHIP BETWEEN THE FOLK ARTS IN} HUNAN AND THE TEACHING OF PACKAGE DESIGNING

The folk arts of Hunan is an important marker of Huxiang culture which manifests the localness and traditional art culture; the treasury of folk arts in Hunan provides abundant drawing resources and artistic expressions, which can bring inspirations and enlightenment for the teaching of package designing. Hunan is situated in the south of Dongting Lake and also is the birthplace of Chu culture as well as the literature garden of Xiang\&Chu in every dynasty. The folk arts in Hunan have a long history and profound cultural deposits and unique humanistic style, which form distinct local folk arts with its own characteristics in the thousands of years of cultural development in China. Hunan is rich in natural resources and the products with the features of Huxiang often are quite popular in both home and abroad. However, by our marketing research, it is found that the packages for the products with Huxiang's features are mainly plastic and are lack of the consciousness of humanism. Though some of the package is the traditional decorative patterns, it is short of the local characteristic of Hunan. For example, some packages use the dragon pattern which is common pattern in the package design as well as a unique pattern in Chinese folk culture due to its majesty and aggressiveness, but in the folk arts of Hunan, the dragon pattern in west Hunan goes through the regional evolution and these majesty and aggressiveness become magic and loveliness. The ratio between the dragon's head and body is shortened and it is with big head and clumsy posture which is of utterly different visual feelings with the dragon pattern of Beijing. In some packages of Huxiang's specialty, it can be seen that the dragon patterns are the dragon patterns of Chinese folk arts rather than the dragon patterns with the artistic sentiment of Hunan's folk arts. Let set another example, the Jiang Tang of south Hunan is popular all over the country. However, according to our market research, the packages are mainly plastic. Though cheap, it is not environment-friendly. In the research, though the package designing of one specialty is made of paper and with traditional decorative style, it can be found that the decorative pattern on the package is Riverside Scene at Qingming Festival by scrutiny.

Throughout most of the package designing in the market, apart from signing that the designing is lack of regional characteristics, it should also be retrospected that as vocational colleges which are built for cultivating designers, does the teacher pay any attention to the teaching of local regional culture? Does the teacher guide the students to have a clear understanding of the regional culture where they are born and live? Does the teacher make the student learn the folk arts of Hunan which Hunan has nourished for thousands of years? When the students graduate from college, begin to work and come across the package design, they can have one additional designing skill in their designing methods by our cultivation and guidance, which is their accomplishment of local folk arts.

\section{THE STATUS QUO OF THE APPLICATION OF FOLK ARTS IN HUNAN INTO THE TEACHING OF DESIGNING}

At present, in the courses of artistic designing, there are two basic courses, namely history of Chinese arts and crafts and history of modern design. History of Chinese arts and crafts is set as the theoretical basis courses for the students of artistic designing while history of modern design cannot elaborated into the folk arts of each provinces due to its large scope. But the folk arts in our province are exactly the features of regional culture for each place. If anyone asks that why he buys similar specialty in each places during traveling, after all, it is because that the folk arts in each place is the visual performance that distinguishes the regional specialty of each place. If is applied into the package design, it is indeed that all flowers bloom together and everything is different. Furthermore, in the development background of the folk arts of Hunan in the new era, the involved scope is smaller and smaller. If it can be combined with the teaching of modern artistic design before declining, it is also the inheritance and development of the times. Up to now, there are quite few packages with the package design of 
Hunan's feature, still much more less package that can manifest the cultural features of the folk arts in Huxiang. In the native Hunan, Phoenix in west Hunan and Zhangjiajie is popular tourist sites in China, but the packages of the specialty within scenic spots are quite the same with the packages in other tourist sites in China. The reason lies in that it lacks the cultural connotations with local regional features. Since folk arts are the source of the inspiration for the package designing, if the students can systematically understand and learn the artistic cultural features of the folk arts in Hunan, it will inevitably promote the education of artistic design in our province because that the inheritance and development of culture should combine with the artistic design of regional features. And young people should bear these responsibilities. As designing teaching staff in the high school, the teachers have the responsibilities and obligations to make the students understand our local folk arts, grasp the folk arts in Hunan by learning and understanding and absorb the designing inspiration from the culture and arts instead of pushing them away from folk arts, which will drive our inheritance from the local folk arts of the artistic education as well as promote the designing accomplishment and quality of our students. Meanwhile, by the designing of the combination of the programs and folk arts guided by course, it can also promote the commercial values of the package designing of the local specialty of Hunan.

\section{THE IMPLEMENTATION OF THE FOLK ARTS OF HUNAN IN THE TEACHING OF PACKAGE DESIGNING}

Above all, in the teaching of the course practices of package designing, the introduced top is the "package design of the specialty of their hometown". Hunan is with more than 60 million people and vast territory. West Hunan, midHunan and North-Hunan are with quite different artistic styles. In the folk arts of Hunan, the artistic performance of each place is different. For example, the paper-cuts in west Hunan is mainly to dig which is much refined, while the paper-cuts in Hunan Liuyang is slightly wild and the patterns and contents of the paper-cuts are quite different from west Hunan. By making the courseware, the students will have a systematic understanding the category of Hunan's folk arts. The performance characteristic of each category in the folk arts of Hunan and the difference in the patterns with regional features of each category will make the students have a better understanding of the artistic features and artistic performance forms of the folk arts of Hunan and prepare for the aesthetic quality before designing, therefore they can "write fluently by reading thousands of books" during the designing of package.

\section{A. Lead-in of the subject——making the packing design with the regional features of Huxiang}

The lead-in of the subject starts after the students have some knowledge about the various categories of the folk arts in Hunan and diverse features of artistic expression. The title of the subject is "the package design for the specialty in your hometown". All the students come from different places or cities, so they are most acquaint with the specialty in their hometown as well as the advantages and disadvantages of the packages of the specialty in their hometown, such as the blood brean curd ball, Longya lily in Hunan Shaoyang, fireworks and firecrackers in Liuyang, bamboo crafts in Yiyang, Jiangtang in west Hunan, Kiwi fruits in Zhangjiajie, Ma Xianggao in Yuan Jiang etc. To make the students do the package design for the products they are familiar can also increase the students' interests on the practical teaching of the courses and enrich the expressive categories of the tasks for the subjects. Besides, by designing the packages for the specialty in their hometown, the students' designing results can improve the visual images of the packages for local specialty, manifest the glamour of regional culture, which also encourage and affirm the designing ability of the students.

\section{B. In-depth comprehending - the folk arts in Hunan is the source for the inspiration of the package design}

By applying the folk arts of Hunan into the package design, the students can have an in-depth understanding of the folk arts in Hunan. By filed observation, marketing research, investigation of the package design projects, study and analysis on the literature materials and so on, the students can fully play their initiatives for active learning and consider the relevancy between the folk arts in Hunan and the package design for the specialty of their hometown. By in-depth study and the use of initiatives, the students are conscious of the artistic glamour of the folk arts in Hunan and dig out the artistic features of the folk arts in Hunan. The students of designing major can bear in mind the folk arts in Hunan with thousands of years of the Wu-Chu's cultural features, which will become the treasury for their design as well as the sources for their inspiration.

\section{Refining the elements_—inheritance and flourishing the folk arts in Hunan}

The folk arts in Hunan is diverse and with various expressions, such as the New Year pictures in Shaoyang Tantou, paper-cuts in west Hunan, Brocade of Tujia nationality, batik in Phoenix etc. By the guidance of the teachers, the students can apply the image elements, color elements, expression forms of textures etc. refined from the folk arts in Hunan into the projects. For example, the folk arts in Hunan are with rich images. By the designing orientation of earlier stage, the designers can change, reorganize or disperse the structure of the images of the elements selected from the folk arts to some extent, which can make them equip with the forms and romantic charms of the folk arts as well as the connotation of modern design. But the premise for converting these images elements of the folk arts lies in that they cannot affect the image styles and the connotation. The techniques can be summarized as follows. Firstly, simplification of the images, to refine the images, it can simply expressed by lines and combine the artistic expression of modern decoration arts. Secondly, exaggerate parts of the refined elements of the folk arts in Hunan by the artistic techniques. Thirdly, reorganize the images of folk arts can not only maintain the connotation of the traditional patterns and images of the image arts but also combine the techniques of graphic arts which can present the style and 
sentiment of the modern artistic design. Fourthly, organize the images according the beauty in forms and apply them into the package and decoration. The application of the elements of the traditional folk arts in Hunan is not only to simply copy the image or to simply collage; instead, it is to refine the folk arts in Hunan by the artistic expression of package design after strategic analysis of the package design and the positioning of the package design project. Of course, the difference in contents packaged, the artistic expression and the material used will all account for the diverse final visual effects.

\section{Applying to use and beauty--applying the elements of the folk arts in Hunan into the practice of the teaching for package design}

In the teaching practice for package, the students can encourage the students to innovate boldly. The elements of the folk arts in Hunan contain diverse graphic elements which is the arts of visual. Application them into the package design can change their exterior adornment, enrich and beautify the external images, deepen the internal cultural values and improve additional value of the package design. For example, firstly, use the hollow opening design in the package directly; secondly, applying the images of the folk arts in Hunan into the design of graphic decoration. On the one hand, the appearance of the packaged products is decorated and the design techniques for the design of adornment arts create the special package with the unique regional characteristics. The application of the image patterns is the common decoration method. With the folk arts elements of Hunan, the pattern is not only beautiful but also manifests the unique regional culture. The auspicious patterns of the folk arts in Hunan have already become household in people's life. The pattern they are familiar makes it easy for them to understand the connotation. The traditional auspicious patterns with abundant connotations represent the best wishes for praying for good life and the teachers can guide the students to refine the patterns with the auspicious meaning. In the collocation of colors, the teachers can guide the students refine from the folk arts such as Brocade of Tujia nationality and New Year pictures of Tantou. And the teachers can make these traditional colormatching into the chromatography table which can be used as reference when the students match the colors. The traditional color-matching is fond of the colors with high saturability which is the color of nature and can best represent the abstract images of the folk arts in Hunan. The color collocation of the traditional folk arts is applied into the teaching practice of the package design. By the performance of the later package, it can highlight the unique cultural glamour of the folk arts in Huxiang.

\section{APPLICATION OF THE FORMS.}

To refine the forms of the folk arts in Hunan should make the students analyze the diverse category of the folk arts in Hunan and the forms expression forms that best suit for the subject. By filtering it by themselves and the guidance of the teachers, the students can select the pattern elements that can best express the artistic conception of the local culture in
Huxiang, reorganize, change elements and introduce new elements, which can make it not only have the romantic charms of the folk arts in Hunan as well as the implication of modern design. In the teaching practice of the package design, the package design of the Jiangtang of Liu introduces the pattern of the paper-cuts in the play of Tuanhua- Gods of Hehe in the folk arts of Hunan and takes the Gods of Hehe as the traditional auspicious patterns. It combines the modern layout style and the traditional scheduling arts which make the whole page have high visual shock. The selection of Kraft material as the package material is not only environment-friendly but also can awake people's nostalgic sentiment. The red color can remind people of the previous old package form which make the package design traditional as well as modern. The paper-cuts patterns used are the paper-cuts patterns of the folk arts in Hunan, which can highlight the regional cultural features of Huxiang.

\section{APPLICATION OF THE COLORS}

Hans Hofman once said that color, as a unique language, is full of strong expression all by itself. The folk arts of Hunan are diverse and the expressive features of arts of colors are obvious. The splendor and enthusiastic colors of pictures, the abundant and orderly colors of brocade and the magnificent, romantic and legendary colors of embroidery and the pure, unique and nature blue colors of batik are worthy of the understanding and mater of contemporary students of designing major. The color collocation of the folk arts in Hunan reflects the praying for better life and the optimistic romantic spirits of the people's inner heart. The combination of these colors can represent simple, elegant, peaceful and coordinated artistic style as well as decorative artistic beauty full of strong comparison between colors and booming which is the expression of the colors of Huxiang that are full of unique Huxiang features as well as the color collocation arts that distinguish it from the folk arts in other provinces. By the teaching practice of the package design, the teachers can guide the students to apply it in the package for the specialty of their hometown and use the modern designing expression to show abundant color sentiment which can highlight different regional culture. Take the package design of Tablet Sugar as an example. The refined color is bold. The comparable colors that are pure saturation origin from the New Year Pictures of Tantou in the folk arts of Hunan which favors the use of high saturated colors, such as red (red lead), yellow (bright yellow) and blue(royal blue) and the hue is warm and is assisted by light green, pale purple, rose and grey. The New Year Picture of Tantou pay much emphasis of the comparison between warm and cold, the comparison of area and the similar colors, whose techniques of collocation of colors is used as reference and applied into the package design of Tablet Sugar and produce rich visual effects of colors. The patters origins from the paper-cuts patterns such as tiger, birds and Chinese dragon, of the folk arts in Hunan, which is full of unique features and is much more uncomplicated and lovely than common papercuts patterns. The exaggerated head and tail and the ration between the head and body is shrinked. The design style is 
concise and changeable which is very magnificent by applying into the package design of Tablet Sugar.

Apart from the use of forms and colors, there are other artistic expression, such as material and so on which will not be discussed on by one. The diverse artistic expression of the folk arts in Hunan is like an inexhaustible cultural and artistic treasury. This paper only uses some for the exploration of the teaching practices. The application of the folk arts in Hunan into the teaching practices of High school that can be dug is endless.

\section{CONCLUSION}

As educators for artistic education, apart from teaching the students the designing techniques, the teachers should improve the students' cultural connotation, pay attention to the teaching of local folk arts into the modern design. By introducing the folk arts in Hunan into the courses of local designing major, it cannot manifest the value of the tradition folk arts of Hunan in the modern artistic design, improve the expressive forms of the package design for the regional specialty, but also can increase the students' interests in designing. By initiative thinking and exploration and combining the traditional folk arts of Hunan with the package design of specialty in designing practice, it is the better combination of arts and skills which will be carried on by the further and subsequent designing courses.

\section{References}

[1] Jin Ke.Traditional Folk Arts and Package designing [J] .Packaging Engineering, 2007, 28(8)

[2] Fang Yuan.Interpretation of the educational effects of the artistic features of Brocade of Tujia nationality on designing [ $\mathbf{J}]$ Nationalities Forum,2008, (7)

[3] Zhang Yi \& Huang Liang Brief Introduction on the Application of Folk Arts in Modern Package Designing $[\mathrm{J}]$ Journal of Xianning University,2012,32(9)

[4] Wu Wei \& Shan Hefei.Qin Shubao and Yu Chigong-- Exploration on the Gate-God Picture of Old-style Military Commanders [J]. Designing Online Features.2006(9)

[5] Zuo Hanzhong.Collections of folk arts in Hunan[M]Changsha : Hunan Fine Arts Publishing House, 1994

[6] Hu Shouhai.Principles on Designing Aesthetics [M] Hefei : Hefei University of Technology Publishing House, 2011 